\title{
Ability of a Urine Assay of Type II Collagen Cleavage by Collagenases to Detect Early Onset and Progression of Articular Cartilage Degeneration: Results from a Population-based Cohort Study
}

\author{
A. Robin Poole, Nhuan Ha, Suzanne Bourdon, Eric C. Sayre, Ali Guermazi, and Jolanda Cibere
}

\begin{abstract}
Objective. To evaluate the association of a sandwich assay for cartilage collagenase-mediated degradation, the $\mathrm{C} 2 \mathrm{C}$ human urine sandwich assay (IB-C2C-HUSA), with early and late knee cartilage pathology and with progression of cartilage damage.

Methods. A population-based cohort with knee pain, age 40-79 years, was evaluated at baseline $(\mathrm{n}=$ $253)$ and after mean 3.3 years $(n=161)$. We evaluated the IB-C2C-HUSA and a related competitive inhibition assay $(\mathrm{C} 2 \mathrm{C})$. The $\mathrm{C} 2 \mathrm{C}$ assay was applied to serum $(\mathrm{sC} 2 \mathrm{C})$ and urine $(\mathrm{uC} 2 \mathrm{C})$. Based on knee radiographs and magnetic resonance imaging (MRI), 3 subgroups [no cartilage pathology, preradiographic cartilage pathology, and radiographic osteoarthritis (ROA)] were evaluated cross-sectionally for association with biomarker levels. Longitudinally, we evaluated whether baseline assays predict subsequent progression of cartilage degeneration, defined by MRI cartilage loss.

Results. Cross-sectionally, statistically significant differences were seen in the 3 subgroups for IB-C2C-HUSA $(p<0.001)$, with the highest levels seen in ROA, and for $\mathrm{sC} 2 \mathrm{C}(\mathrm{p}=0.023)$, while no differences were seen for $\mathrm{uC} 2 \mathrm{C}(\mathrm{p}=0.501)$. Baseline IB-C2C-HUSA levels were higher in progressors vs nonprogressors $(\mathrm{p}=0.003)$. In logistic regression analysis, only baseline IB-C2C-HUSA was associated with an increased risk of progression of cartilage damage (OR 1.78, 95\% CI 1.03-3.09). Conclusion. The IB-C2C-HUSA degradation assay detects the generation of a pathology-related cartilage collagen peptide(s) that increase(s) with onset of degeneration of knee articular cartilage. The baseline values are associated with progression of cartilage degeneration over 3 subsequent years. This assay may have value in clinical OA trials. Further, it points to collagenase activity as a therapeutic target for controlling degeneration of articular cartilage. (First Release August 1 2016; J Rheumatol 2016;43:1864-70; doi:10.3899/jrheum.150917)
\end{abstract}

Key Indexing Terms:

OSTEOARTHRITIS

\section{TYPE II COLLAGEN}

\section{IMMUNOASSAY}

From the Division of Orthopedics, Department of Surgery, Faculty of Medicine, McGill University, Montreal, Quebec; R\&D Diagnostics, IBEX Pharmaceuticals, Montreal, Quebec; Arthritis Research Canada, Richmond, British Columbia, Canada; Department of Radiology, Boston University School of Medicine, Boston, Massachusetts, USA; Department of Medicine, University of British Columbia, Vancouver, British Columbia, Canada.

The cohort study was funded by grants from the Canadian Institutes of Health Research (\#89890, \#89997), the Canadian Arthritis Network (01-MNO-09N), and The Arthritis Society (TASO4/0063). Dr. Cibere was supported by an Investigator Award from The Arthritis Society (INS-12-027). A.R. Poole, PhD, DSc, Professor Emeritus, Division of Orthopedics, Department of Surgery, Faculty of Medicine, McGill University; N. Ha, PhD, Manager, R\&D Diagnostics, IBEX Pharmaceuticals, currently affiliated with Beckman Coulter, Miami, Florida, USA; S. Bourdon, BSc, Manager, Assay Production, IBEX Pharmaceuticals; E.C. Sayre, PhD, Statistical Analyst, Arthritis Research Canada; A. Guermazi, MD, PhD, Professor, Department of Radiology, Boston University School of Medicine; J. Cibere, MD, PhD, Associate Professor, Department of Medicine, University of British Columbia, and Senior Scientist, Arthritis Research Canada.

Address correspondence to Dr. J. Cibere, Arthritis Research Canada, 5591 No. 3 Road, Richmond, British Columbia V6X 2C7, Canada. E-mail: jcibere@arthritisresearch.ca

Full Release Article. For details see Reprints/Permissions at jrheum.org Accepted for publication June 17, 2016.
Cartilage matrix has an extensive fibrillar type II collagen network that confers tensile strength to hyaline cartilage. In early degeneration of articular cartilages and in osteoarthritis $(\mathrm{OA})$, the extracellular matrix is degraded, involving often irreversible cleavage of the triple helical domains of the fibrillar type II collagen. This involves collagenases, such as matrix metalloprotease 13 and cathepsin $\mathrm{K}^{1,2,3,4,5,6,7,8,9}$.

A monoclonal antibody (C2C)-based competitive inhibition immunoassay specific for the cleavage of type II collagen by collagenases ${ }^{8}$ had limited value in detecting early onset of OA and its progression ${ }^{10,11}$. Analyses of type II collagen fragments revealed that a 45 -mer peptide was increased in the urine of patients with OA compared to healthy donors ${ }^{12}$ : this contained the $\mathrm{C} 2 \mathrm{C}$ neoepitope. A sandwich assay was created (IB-C2C-HUSA; IBEX Pharmaceuticals, where HUSA represents human urine sandwich assay) to quantitate this 45 -mer fragment in human urine in health and pathology. We describe this new urine assay and its application and compare it to the original C2C assay in a population-based longitudinal cohort study. 


\section{MATERIALS AND METHODS}

The population was recruited between 2002 and 2005 and described previously ${ }^{11,13}$. Briefly, subjects 40-79 years old with knee pain were recruited as a random population sample in Vancouver, British Columbia, Canada, using stratified sampling to achieve equal representation within age decades and between men and women. Subjects were excluded at baseline if they had inflammatory arthritis, fibromyalgia, knee arthroplasty, knee injury or surgery within the previous 6 months, referred pain, or magnetic resonance imaging (MRI) contraindications. Exclusion criteria at followup were knee arthroplasty, inflammatory arthritis, MRI contraindications, comorbidity, or inability to attend the study center ${ }^{14}$.

Subjects provided written informed consent. The study was conducted in accordance with the Declaration of Helsinki and was approved by the Clinical Research Ethics Board, University of British Columbia.

Clinical and radiological evaluations. Subjects were evaluated at baseline $\mathrm{e}^{11,13}$ and followup ${ }^{14}$ after a mean of 3.3 years for symptoms, OA risk factors, and with Western Ontario and McMaster Universities (WOMAC) OA Index, visual analog scale $3.1^{15}$. The more symptomatic knee was the study knee.

Baseline and followup knee radiographs were obtained within a month of clinical assessment, using a fixed-flexion technique with the SynaFlexer positioning frame $\mathrm{e}^{16}$ and supine skyline view ${ }^{11,13,14}$. Radiographs were scored blinded to clinical and MRI information by 2 independent readers using the Kellgren-Lawrence (KL) 0-4 grading ${ }^{17}$, which evaluates the tibiofemoral compartments. The interrater reliability was excellent, with an intraclass correlation coefficient of $0.79^{11}$. Differences in readings were adjudicated by consensus readings of the 2 readers.

Baseline and followup MRI were obtained on a GE Healthcare 1.5T magnet within a month of the clinical assessments. Four MRI sequences were obtained, as described ${ }^{11,13,14}$ : (1) fat-suppressed T1-weighted 3-D spoiled gradient echo in the sagittal plane with axial and coronal reformat images; (2) fat-suppressed T2-weighted fast spin echo (FSE) in coronal plane; (3) T1-weighted FSE in oblique sagittal plane; and (4) T2-weighted FSE in oblique sagittal plane.

Six joint regions were assessed: medial and lateral tibia, medial and lateral femur, patella, and trochlear groove. Cartilage was graded on a 0-4 semiquantitative scale, based on the following definitions, described by Disler, et $a l^{18}$ : 0 = normal; 1 = abnormal signal without cartilage contour defect; $2=$ cartilage thickness defect of $<50 \% ; 3=$ cartilage thickness defect of $50 \%-99 \% ; 4=100 \%$ cartilage thickness defect with subjacent bone signal abnormality ${ }^{11,13,14}$. Baseline and followup images were read side by side, blinded to time sequence, by a single reader (AG) who was blinded to radiographic and clinical information. Intrarater reliability of cartilage readings ranged from 0.84 to 1.0 for different regions ${ }^{11}$.

Based on radiographic and MR cartilage (MRC) scores (using the worst cartilage lesion of any of the 6 regions), subjects were classified into 3 subgroups, defined as follows: (1) no cartilage pathology (NCP): $\mathrm{MRC}=0$ and $\mathrm{KL}<2$; (2) preradiographic cartilage pathology (PRCP): $\mathrm{MRC} \geq 1$ and $\mathrm{KL}<2$; (3) radiographic OA $(\mathrm{ROA}): \mathrm{MRC} \geq 1$ and $\mathrm{KL} \geq 2^{11,13,14}$. Progression of cartilage damage was defined as worsening of cartilage score of $\geq 2$ grades in at least 1 region or worsening of cartilage score of $\geq 1$ grade in at least 2 regions from baseline to followup, as described ${ }^{14}$.

Biomarker evaluations. Serum (s) and urine (u) samples were collected at baseline study visit with details of specimen collection and storage described ${ }^{11}$. Samples were collected between 10 AM and 3 PM. Sera were assayed with the serum $\mathrm{C} 2 \mathrm{C}(\mathrm{sC} 2 \mathrm{C})$ assay, expressed as $\mathrm{pg} / \mathrm{ml}$. Urine samples were assayed using both $\mathrm{C} 2 \mathrm{C}$ assays: $\mathrm{uC} 2 \mathrm{C}$ ( $\mathrm{sC} 2 \mathrm{C}$ assay applied to urine) and IB-C2C-HUSA. All assays were performed in duplicate. Urine creatinine was assayed as described ${ }^{11}$. Assay results were expressed as $\mathrm{ng} / \mathrm{mmole}$ creatinine. Picomole concentrations of type II collagen fragments were determined from ng values using molecular weights of assay standards. This permitted comparison of pmole concentrations of molecular fragments in urine that bears the $\mathrm{C} 2 \mathrm{C}$ neoepitope, determined by the assays IB-C2C-HUSA and uC2C.
Biomarker immunoassays. The commercial IB-C2C-HUSA (IBEX) is designed primarily to detect a type II collagen 45-mer collagenase-generated cleavage fragment most commonly found in human urine ${ }^{12}$. This C-terminal cleavage neoepitope is recognized by the $\mathrm{C} 2 \mathrm{C}$ monoclonal antibody ${ }^{8}$ and its presence on type II collagen fragments is detected in a sandwich assay in combination with capture antibodies. Capture antibodies were all specific for the intrachain epitope with sequence GEP GDD GPS. This sequence is separated from the downstream $\mathrm{C} 2 \mathrm{C}$ neoepitope EGP PGP QG, recognized by antibody $\mathrm{C} 2 \mathrm{C}$ by the sequence GA. The capture antibody preparation contains a mix of $\gamma$ globulin derived from a chicken antiintrachain epitope antiserum and $\gamma$ globulin of a murine monoclonal antibody 510912,19 (American Type Culture Collection Accession Number ATCC-HB-12435). The chicken $\gamma$ globulin was affinity purified from polyclonal antisera commercially prepared in chickens against keyhole limpet hemocyanin-conjugated peptide intrachain epitope GEP GDD GPS (all by Gallus Immunotech Inc.). Both monoclonal antibodies (5109 and C2C) were protein A purified and monoclonal antibody $\mathrm{C} 2 \mathrm{C}$ was labeled with horseradish peroxidase (HRP; labeling is proprietary). Capture immunoglobulin concentrations are also proprietary. The standard curve uses a 21 -mer peptide according to the human sequence ${ }^{12}$, EK GEP $(O H) G D D G P S$ GA $E G P P(O H) G P Q G$ (prepared by American Peptide) incorporating the 2 epitopes shown in italics, where $\mathrm{OH}$ signifies hydroxylation.

The IB-C2C-HUSA assay is conducted at room temperature. Precoated 96-well high-binding immunoassay plates (Biomat) containing capture antibodies to the intrachain epitope $(120 \mu \mathrm{l} /$ well) are prepared by binding antibodies overnight at $5^{\circ} \mathrm{C}$ in $0.5 \mathrm{M}$ sodium carbonate buffer, $\mathrm{pH}$ 9.6. Plates are then washed 5 times with $350 \mu \mathrm{l} /$ well of $0.10 \mathrm{mM}$ potassium phosphate, $\mathrm{pH} 7.4$ washing buffer, to remove unbound antibody. Here and elsewhere an automated microplate washer was used (Bio-Tek Instruments Inc.). To separate Corning 96-well microplates are added $30 \mu \mathrm{l}$ of standard or controls (proprietary solvent) or sample to $30 \mu \mathrm{l}$ proprietary matrix buffer. Then, 60 $\mu 1$ of dilution buffer [phosphate buffered saline (PBS) $+0.5 \% \mathrm{w} / \mathrm{v}$ bovine serum albumin; diagnostic grade, Millipore] is added to each well. After gentle mixing, $100 \mu \mathrm{l}$ of the premixed solutions are transferred to the precoated plates that are incubated for $60 \mathrm{~min}$. After incubation, the plates are washed 5 times with $350 \mu 1 /$ well washing buffer (PBS- $0.05 \% \mathrm{v} / \mathrm{v}$ Tween). Then, $100 \mu 1 /$ well of HRP-labeled C2C antibody (proprietary information) is added and plates are incubated for another $30 \mathrm{~min}$. After incubation, the plates are washed 5 times with washing buffer. Then $100 \mu \mathrm{l}$ of $3,3^{\prime}, 5,5^{\prime}$-tetramethyl-benzidine peroxidase substrate in acidic buffer containing $0.1 \% \mathrm{H}_{2} \mathrm{O}_{2}$ (KPL Inc.) is added to each well. After $30 \mathrm{~min}, 100$ $\mu \mathrm{l}$ of $0.2 \mathrm{M} \mathrm{H}_{2} \mathrm{SO}_{4}$ is added to each well to stop the reaction. Absorbance at $450-650 \mathrm{~nm}$ is measured with an ELISA plate reader (Molecular Devices) and the concentration of unknown samples determined by reference to the standard curve.

The $\mathrm{SC} 2 \mathrm{C}$ assay for detecting specific type II collagen cleavage by collagenases has been described in detail ${ }^{8}$. In this study, this assay, when applied to urine, is referred to as $\mathrm{uC} 2 \mathrm{C}$. The standard used in this $\mathrm{C} 2 \mathrm{C}$ assay is CGGEGP (Hyp)GPQG. These 2 assay standards for $\mathrm{C} 2 \mathrm{C}$ and IB-C2C-HUSA were used to calculate pmole concentrations detected by each of these assays when examining urine.

Although both assays involve detection of the same neoepitope (C2C), the IB-C2C-HUSA assay also detects an intrachain epitope that is specific to type II collagen. Thus, this sandwich assay can detect only fragments of type II collagen that contain both these epitopes. In contrast, the $\mathrm{sC} 2 \mathrm{C}$ and $\mathrm{uC} 2 \mathrm{C}$ competitive inhibition assays (which are identical, but the letter preceding $\mathrm{C} 2 \mathrm{C}$ indicates whether it is applied to either serum or urine) will detect any fragments containing the $\mathrm{C} 2 \mathrm{C}$ neoepitope, including those that lack the intrachain epitope, which by definition will be smaller than any detected by the IB-C2C-HUSA. The IB-C2C-HUSA is designed to detect the dominant 45 -mer fragment in urine (demonstrated previously by very sensitive mass spectrometry) and any larger fragments (not detected to date by any available technology).

Statistical analysis. Data were summarized as means and SD according to the above defined NCP, PRCP, and ROA subgroups for the cross-sectional

Personal non-commercial use only. The Journal of Rheumatology Copyright (C) 2016. All rights reserved. 
analysis and by progression group for the longitudinal analysis. Medians and 25th and 75th percentiles are presented in Supplementary Table 1 (available online at jrheum.org). Biomarker means for each of the subgroups were compared using ANOVA. For the purpose of regression analyses, biomarker data were log-transformed, which resulted in normally distributed data based on quantile-quantile plots. To evaluate the association of the biomarker and its relationship to specific subgroups, multinomial logistic regression analysis was performed to determine the OR and $95 \%$ CI of the variable's association with subgroup status for each of the following comparisons: (1) ROA versus NCP, (2) PRCP versus NCP, and (3) ROA versus PRCP. For the longitudinal analysis, logistic regression analysis was performed to evaluate the association of the biomarker with progression of cartilage pathology. All analyses were adjusted for age, sex, and body mass index (BMI). Additional sensitivity analysis was performed adjusting for baseline ROA in the longitudinal analysis. Reported OR reflect an increment of $1 \mathrm{SD}$ of the log-transformed biomarker. Standardization was done to introduce comparability among effects of biomarkers, which are measured on different scales. Expressing effects in terms of "per SD" allows a comparison of the OR across biomarkers. Log transformation was done to improve the normality of the biomarker variables, and thus improve the interpretability of an effect expressed as "per SD." Receiver-operating characteristic (ROC) curves were generated for each of the comparisons cross-sectionally and longitudinally for each biomarker. Area under the curve (AUC) statistic was calculated. To obtain population-based estimates, analyses were performed using age decade-sex stratum sampling weights Analyses were performed using SAS v9.4.

Table 1. IB-C2C-HUSA assay: intraassay and interassay variation.

\begin{tabular}{|c|c|c|c|c|c|}
\hline \multirow[b]{2}{*}{ Sample } & \multirow[b]{2}{*}{ Mean, pg/ml } & \multicolumn{2}{|c|}{ Intraassay $\leq 4.8 \%$} & \multicolumn{2}{|c|}{ Interassay $\leq 6.7 \%$} \\
\hline & & $\mathrm{SD}, \mathrm{pg} / \mathrm{ml}$ & $\% \mathrm{CV}$ & $\mathrm{SD}, \mathrm{pg} / \mathrm{ml}$ & $\% \mathrm{CV}$ \\
\hline Low & 593 & 28 & 4.8 & 40 & 6.7 \\
\hline Medium & 2436 & 67 & 2.8 & 105 & 4.3 \\
\hline High & 3714 & 103 & 2.8 & 137 & 3.7 \\
\hline
\end{tabular}

IB-C2C-HUSA: C2C human urine sandwich assay; CV: coefficient of variation.

\section{RESULTS}

Performance of IB-C2C-HUSA. The assay standard curve is shown in Figure 1. Sensitivity ranged from 156-5000 pg/ml. Interassay coefficient of variation (CV) was determined as the mean concentration and SD with each sample measured in quadruplicate on 3 plates, from 3 different pilot batches, by 3 different operators, for a total of 108 replicates on 27 plates $(n=27)$. For the intraassay $\mathrm{CV}$, assays were also done in quadruplicate for each sample. The percent $\mathrm{CV}$ for each sample (set SD divided by the set mean concentration) were thus derived from 27 sets of quadruplicate data. Intraassay percent $\mathrm{CV}$ also denoted the mean of the 27 individual $\mathrm{CV}$ where $\mathrm{n}=4$ for each sample. Reproducibility was $\leq 4.8 \%$ for intraassays and $\leq 6.7 \%$ for interassays (Table 1 ).

Dilution linearity of samples was measured as undiluted, $1 / 2,1 / 4$, and $1 / 8$ in dilution buffer for each of 4 different urine samples of known C2C concentration. Correlation coefficients were of $\mathrm{r}^{2}>0.99$ across assay range with average dilution recovery of $103 \%(88 \%-124 \%)$. Spike recovery (recovery of added standard) was evaluated by addition of 3 different amounts of the standard peptide to 4 different urine samples of known concentrations. A mean analyte recovery of $97 \%(88 \%-112 \%)$ was observed across the assay range.

Cross-sectional clinical results. Of 255 subjects evaluated at baseline, 2 did not have specimens collected and were excluded. Of 253 subjects, $56.3 \%$ were female, mean age was 56.8 years, mean BMI was 26.5, and mean WOMAC pain was 20.5 (Table 2). NCP was seen in $13.6 \%$, while $47.6 \%$ had PRCP and $38.8 \%$ had ROA. Age and BMI were different in the 3 subgroups, with $\mathrm{p}<0.001$ and $\mathrm{p}=0.017$, respectively. Mean (nontransformed) biomarker levels were statistically significantly different in these 3 subgroups for IB-C2C-HUSA $(\mathrm{p}<0.001)$ and for $\mathrm{sC} 2 \mathrm{C}(\mathrm{p}=0.023)$, but not

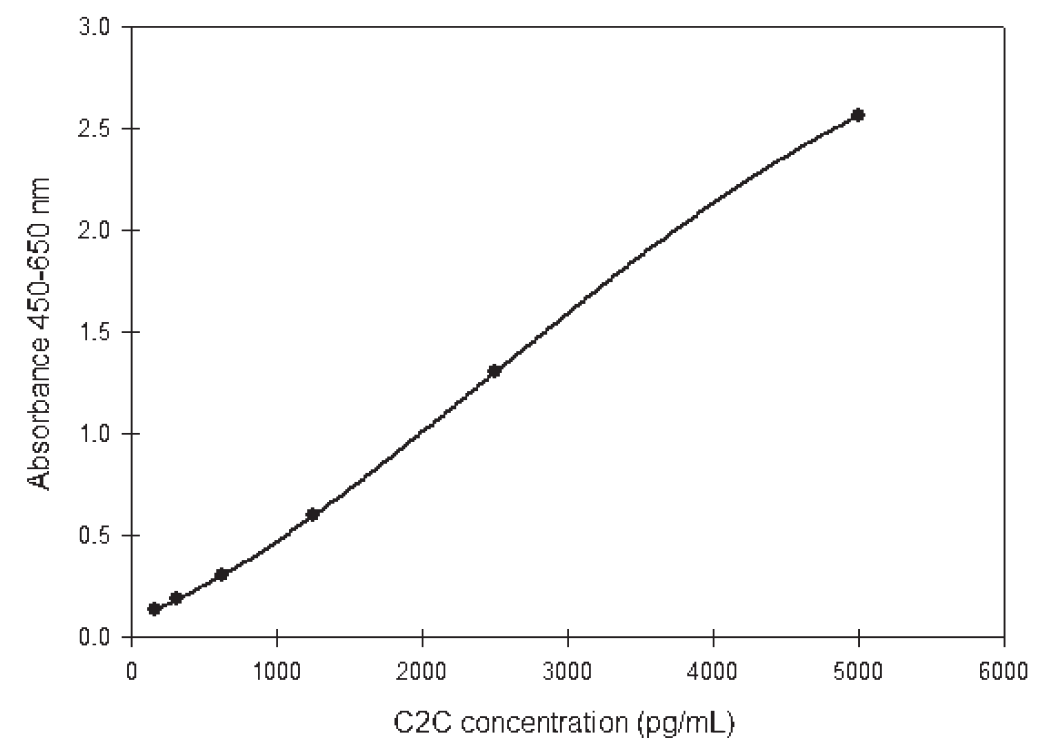

Figure 1. Typical standard curve of $\mathrm{C} 2 \mathrm{C}$ human urine sandwich assay. 
Table 2. Baseline sample characteristics by osteoarthritis (OA) status and by progression status. All data are mean (SD), unless otherwise indicated.

\begin{tabular}{|c|c|c|c|c|c|}
\hline Cross-sectional cohort & $\begin{array}{c}\text { Whole cohort } \\
\text { (weighted } \mathrm{N}=252.5 \text { ) }\end{array}$ & $\begin{array}{c}\mathrm{NCP} \\
\text { (weighted } \mathrm{N}=34.4 \text { ) }\end{array}$ & $\begin{array}{c}\text { PRCP } \\
\text { (weighted } \mathrm{N}=120.1 \text { ) }\end{array}$ & $\begin{array}{c}\text { ROA } \\
\text { (weighted } \mathrm{N}=98.0 \text { ) }\end{array}$ & $\mathrm{p}$ \\
\hline Age, yrs & $56.8(10.4)$ & $49.5(9.9)$ & $54.9(9.4)$ & $61.6(9.6)$ & $<0.001$ \\
\hline Female $(\%)$ & 56.3 & 58.0 & 51.4 & 61.6 & 0.315 \\
\hline $\mathrm{BMI}, \mathrm{kg} / \mathrm{m}^{2}$ & $26.5(4.9)$ & $25.4(4.3)$ & $26.0(4.4)$ & $27.4(5.5)$ & 0.017 \\
\hline WOMAC pain $(0-100)$ & $20.5(17.8)$ & $20.6(16.7)$ & $17.9(18.1)$ & $23.6(17.4)$ & 0.115 \\
\hline Longitudinal cohort & $\begin{array}{c}\text { Whole cohort } \\
\text { (weighted } \mathrm{N}=160.5 \text { ) }\end{array}$ & $\begin{array}{c}\text { No Progression } \\
\text { (weighted } \mathrm{N}=136.1 \text { ) }\end{array}$ & $\begin{array}{c}\text { Progression } \\
\text { (weighted } \mathrm{N}=24.4 \text { ) }\end{array}$ & $\mathrm{p}$ & \\
\hline Age, yrs & $57.7(10.1)$ & $56.9(10.1)$ & $62.1(9.3)$ & 0.021 & \\
\hline Female $(\%)$ & 53.9 & 52.8 & 59.8 & 0.527 & \\
\hline $\mathrm{BMI}, \mathrm{kg} / \mathrm{m}^{2}$ & $26.0(4.2)$ & $26.0(4.3)$ & $25.8(3.6)$ & 0.826 & \\
\hline WOMAC pain $(0-100)$ & $19.6(16.8)$ & $19.1(17.0)$ & $22.6(16.2)$ & 0.344 & \\
\hline Followup time, yrs; range & $3.3(0.6) ; 2.5-5.1$ & $3.4(0.6) ; 2.5-5.1$ & $3.2(0.4) ; 2.9-5.1$ & 0.387 & \\
\hline
\end{tabular}

$\mathrm{P}$ value for percentage female is based on chi-square test; other $\mathrm{p}$ values based on 1-way ANOVA. BMI: body mass index; WOMAC: Western Ontario and McMaster Universities Osteoarthritis Index; NCP: no cartilage pathology; PRCP: preradiographic cartilage pathology; ROA: radiographic OA.

for $\mathrm{uC} 2 \mathrm{C}(\mathrm{p}=0.501$; Figure $2 \mathrm{~A})$. There was a progressive increase in IB-C2C-HUSA with increasing cartilage degeneration.

Based on data shown in Figure 2A and Figure 2B, we can calculate the relative pmole concentrations of the fragments detected in urine with the IB-C2C-HUSA and $\mathrm{uC} 2 \mathrm{C}$, by using the molecular weights of the standards used in these 2 assays. The results demonstrate that the pmole concentration of the fragments measured by the IB-C2C-HUSA is about 14-fold less than that measured by the $\mathrm{uC} 2 \mathrm{C}$.

In the multinomial logistic regression analysis, urine IB-C2C-HUSA was associated with an increased risk of ROA vs NCP (OR 2.90, 95\% CI 1.64-5.13; p < 0.001) and ROA vs PRCP (OR 1.88, 95\% CI 1.27-2.77; $\mathrm{p}=0.002$ ), while PRCP vs NCP (OR 1.55, 95\% CI 0.95-2.50; $\mathrm{p}=0.077$ ) was not statistically significant, with overall $\mathrm{p}<0.001$ (Table 3). $\mathrm{sC} 2 \mathrm{C}$ was associated with ROA compared to PRCP (OR $1.44,95 \%$ CI $1.06-1.97 ; \mathrm{p}=0.022)$, but was not associated with ROA vs NCP (p = 0.809) or PRCP vs NCP ( $p=0.16$; overall $\mathrm{p}=0.052)$. Similarly, no statistically significant associations were found for $\mathrm{uC} 2 \mathrm{C}$ for any of the 3 comparisons (overall $p=0.293$; Table 3 ). ROC curves are shown in Supplementary Figure 1 (available online at jrheum.org). For the prediction of ROA compared to NCP, AUC was 0.889 for urine IB-C2C-HUSA, 0.827 for $\mathrm{sC} 2 \mathrm{C}$, and 0.825 for uC2C. AUC ranged from 0.676 to 0.723 for prediction of PRCP vs NCP and from 0.707 to 0.754 for ROA vs PRCP. For all comparisons, AUC were largest for urine IB-C2C-HUSA, compared to $\mathrm{sC} 2 \mathrm{C}$ and $\mathrm{uC} 2 \mathrm{C}$.

Longitudinal clinical results. Compared to the baseline study population $(\mathrm{n}=253)$, subjects in the longitudinal study $(\mathrm{n}=$ 161) had similar baseline demographic characteristics (Table 2). Progression of cartilage damage was seen in $15.2 \%$ of subjects overall. In those with ROA, $25.2 \%$ progressed compared to $10.4 \%$ and $0 \%$ in the PRCP and NCP groups, respectively. Baseline urine IB-C2C-HUSA (non-log-trans- formed) levels were significantly higher in progressors compared to nonprogressors [mean (SD) 659.8 (446.8) vs 430.9 (215.5), $\mathrm{p}=0.003$ ], whereas no statistically significant differences were seen for $\mathrm{sC} 2 \mathrm{C}$ and $\mathrm{uC} 2 \mathrm{C}$ in progressors compared to nonprogressors (Figure 2B).

In logistic regression analysis (Table 4), the risk of progression was significantly increased with higher levels of urine IB-C2C-HUSA (OR 1.97, 95\% CI 1.14-3.43), while neither sC2C (OR $0.70,95 \%$ CI 0.44-1.12) nor uC2C (OR $0.91,95 \%$ CI $0.59-1.41$ ) were significantly associated with progression of cartilage damage. Sensitivity analysis with further adjustment for baseline ROA showed similar results (Table 4). ROC curves and AUC for prediction of progression are shown in Supplementary Figure 1 (available online at jrheum.org).

Correlations of biomarkers are shown in the Supplementary Table 2 (available online at jrheum.org). Only sC2C and $\mathrm{uC} 2 \mathrm{C}$ were significantly correlated and only in progressors.

\section{DISCUSSION}

By using a combination of IB-C2C-HUSA, measuring cartilage specific collagenase-generated fragments, and both MRI and radiographic analyses, we were able to observe differences between subjects with no cartilage pathology and those with both early and advanced lesions in knee articular cartilage. Further, the risk of disease progression on MRI was increased in subjects with higher levels of this urine biomarker.

The IB-C2C-HUSA assay, described in detail for the first time to our knowledge, is designed to primarily detect a specific dominant 45-mer collagenase-generated type II collagen peptide, previously detected by mass spectroscopy and the type II collagen neoepitope (TIINE) assay, in increased amounts in the urine of patients with $\mathrm{OA}^{12}$. The new IB-C2C-HUSA assay differs from the TIINE assay ${ }^{12,19}$

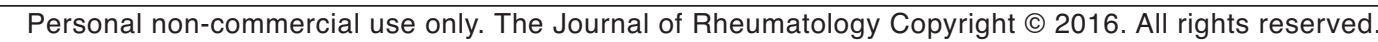


A.
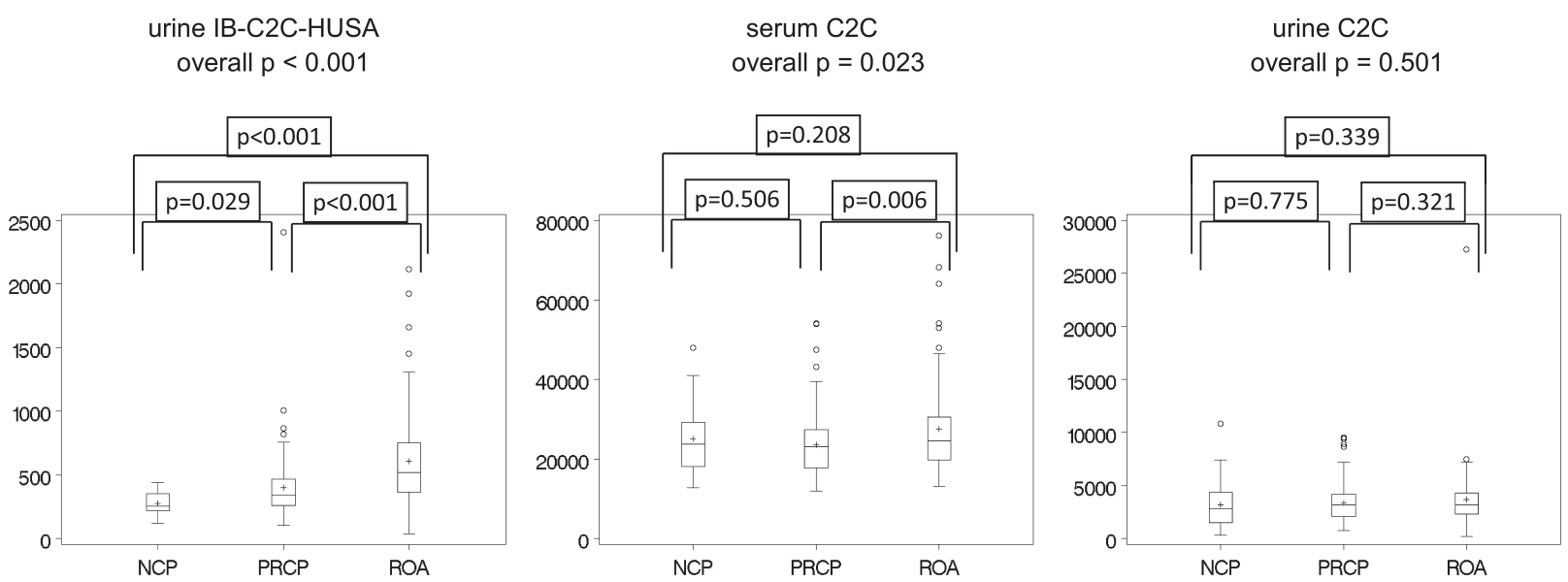

B.
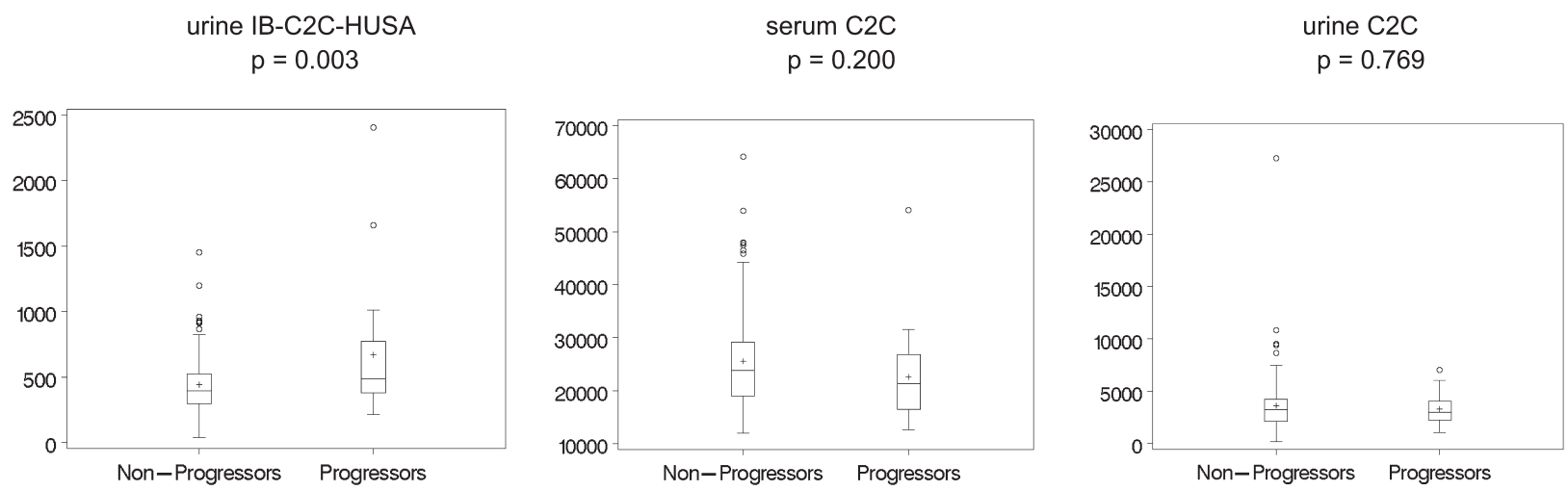

Figure 2. A. Box plots of raw (nontransformed) biomarker baseline data by 3-level cartilage status, showing medians (horizontal line within boxes), interquartile range (boxes), and means (+ within boxes). Units are $\mathrm{pg} / \mathrm{ml}$ for serum $\mathrm{C} 2 \mathrm{C}$ and $\mathrm{ng} / \mathrm{mmol}$ creatinine for urine $\mathrm{C} 2 \mathrm{C}$ and urine IB-C2C-HUSA. P values based on ANOVA. B. Box plots of raw (nontransformed) biomarker baseline data by progression subgroups, showing medians (horizontal line within boxes), interquartile range (boxes), and means (+ within boxes). Units are $\mathrm{pg} / \mathrm{ml}$ for serum $\mathrm{C} 2 \mathrm{C}$ and $\mathrm{ng} / \mathrm{mmol}$ creatinine for urine $\mathrm{C} 2 \mathrm{C}$ and urine IB-C2C-HUSA. P values based on unadjusted logistic regression analysis. IB-C2C-HUSA: C2C human urine sandwich assay; NCP: no cartilage pathology; PRCP: preradiographic cartilage pathology; ROA: radiographic osteoarthritis.

Table 3. Cross-sectional association of log-transformed biomarkers with subgroups using multinomial logistic regression analysis, adjusted for age, sex, and body mass index.

\begin{tabular}{|c|c|c|c|c|c|c|c|c|}
\hline Biomarker & Overall $\mathrm{p}$ value & Effect* & $\begin{array}{l}\text { ROA vs NCP, } \\
\text { OR ( } 95 \% \text { CI) }\end{array}$ & $\mathrm{p}$ & $\begin{array}{c}\text { PRCP vs NCP, } \\
\text { OR (95\% CI) }\end{array}$ & $\mathrm{p}$ & $\begin{array}{c}\text { ROA vs PRCP, } \\
\text { OR }(95 \% \text { CI })\end{array}$ & $\mathrm{p}$ \\
\hline IB-C2C-HUSA & $<0.001$ & 0.55 & $2.90(1.64-5.13)$ & $<0.001$ & $1.55(0.95-2.50)$ & 0.077 & $1.88(1.27-2.77)$ & 0.002 \\
\hline $\mathrm{uC} 2 \mathrm{C}$ & 0.293 & 0.62 & $1.24(0.82-1.86)$ & 0.308 & $1.35(0.93-1.97)$ & 0.119 & $0.92(0.68-1.23)$ & 0.561 \\
\hline
\end{tabular}

* Effect is equivalent to $1 \mathrm{SD}$ of the explanatory variable. NCP: no cartilage pathology; PRCP: preradiographic cartilage pathology; ROA: radiographic osteoarthritis; IB-C2C-HUSA: C2C human urine sandwich assay; sC2C: serum $\mathrm{C} 2 \mathrm{C}$ assay; uC2C: urine $\mathrm{C} 2 \mathrm{C}$ assay.

by use of the type II collagen-specific $\mathrm{C} 2 \mathrm{C}$ antibody rather than monoclonal 9A4. The latter has similar properties, but unlike monoclonal $\mathrm{C} 2 \mathrm{C}$, recognizes both type I and II collagenase-generated primary carboxy-terminal cleavage neoepitope-containing fragments. Thus, although both assays involve detection of the same neoepitope $(\mathrm{C} 2 \mathrm{C})$, the
IB-C2C-HUSA sandwich assay in addition detects an intrachain epitope that is also specific to type II collagen. Hence this sandwich assay can detect only fragments of type II collagen that bear both these epitopes. In contrast, the $\mathrm{C} 2 \mathrm{C}$ competitive inhibition assay will detect any fragments, including those with or without the intrachain epitope. Those 
Table 4. Association of baseline log-transformed biomarkers with cartilage loss over 3 years using logistic regression analysis.

\begin{tabular}{lccccc}
\hline Biomarker & Effect $^{\dagger}$ & OR $(95 \% \mathrm{CI})^{*}$ & $\mathrm{p}$ & OR $(95 \% \mathrm{CI})^{* *}$ & $\mathrm{p}$ \\
\hline IB-C2C-HUSA & 0.54 & $1.97(1.14-3.43)$ & 0.016 & $1.78(1.03-3.09)$ & 0.039 \\
$\mathrm{sC} 2 \mathrm{C}$ & 0.32 & $0.70(0.44-1.12)$ & 0.137 & $0.67(0.41-1.09)$ & 0.108 \\
$\mathrm{uC} 2 \mathrm{C}$ & 0.68 & $0.91(0.59-1.41)$ & 0.675 & $0.93(0.60-1.45)$ & 0.752 \\
\hline
\end{tabular}

$\dagger$ Effect is equivalent to $1 \mathrm{SD}$ of the explanatory variable. * Adjusted for age, sex, and body mass index. ** Adjusted for age, sex, body mass index, and radiographic osteoarthritis. IB-C2C-HUSA: C2C human urine sandwich assay; $\mathrm{sC} 2 \mathrm{C}$ : serum $\mathrm{C} 2 \mathrm{C}$ assay; uC2C: urine $\mathrm{C} 2 \mathrm{C}$ assay.

without the intrachain epitope will, by definition, be smaller than any detected by IB-C2C-HUSA assay. Thus, IB-C2C-HUSA will detect the dominant 45-mer fragment in urine and any larger fragments bearing both the intrachain epitope and the neoepitope. Such larger fragments have not been detected by any technology, including mass spectrometry.

Our observations reveal that by using this sandwich assay, it was possible to identify production in urine of collagenase-generated type II collagen fragment(s) bearing the $\mathrm{C} 2 \mathrm{C}$ neoepitope, but only at greatly reduced pmole concentrations (about 14-fold lower) compared with those measured by the $\mathrm{uC} 2 \mathrm{C}$ competitive inhibition assay. The results show that the more specific urine IB-C2C-HUSA assay detects a subpopulation of fragments in urine that are associated with pathological changes. It is only the IB-C2C-HUSA assay that can discriminate between fragments bearing only the $\mathrm{C} 2 \mathrm{C}$ neoepitope and those bearing both the $\mathrm{C} 2 \mathrm{C}$ neoepitope and the intrachain epitope, such as would be present on the 45 -mer fragment or any other of larger size bearing these 2 epitopes.

The IB-C2C-HUSA assay detected only very low or no concentrations in serum (data not shown). Urine detection by this assay may thus result from glomerular filtration resulting in the concentration from serum of collagenase-generated fragments.

Using the IB-C2C-HUSA urine assay, we found a statistically significant association of the elevated concentration of cartilage collagen fragments with advanced radiographic changes, the latter characterized as OA, as well as an increased risk with early preradiographic cartilage degeneration, although the latter was not statistically significant. Further, in those already exhibiting cartilage pathology, analysis of baseline urine with this assay was predictive of subsequent cartilage loss over 3 years, with progressors exhibiting increased levels compared to nonprogressors. Additional sensitivity analyses with adjustment for baseline radiographic OA did not change these conclusions. Such clear differences between groups and relationships to disease progression were not observed for the $\mathrm{C} 2 \mathrm{C}$ assay when applied to baseline serum and urine samples. These observations indicate that with progressive onset of knee cartilage pathology, there is evidence for the increased involvement of the degradative activity of collagenases degrading cartilage type II collagen as revealed by the increase in the IB-C2C-HUSA assay data with progressive damage to knee articular cartilage. Such elevations of collagenase activity within early focal ${ }^{9}$ and late ${ }^{1,5,6,7}$ lesions in articular cartilage have been previously observed in ex vivo analyses.

$\mathrm{OA}$ is a condition in which the progressive loss of articular cartilage is now viewed as a discontinuous phasic process $^{20,21}$. Therefore the ability to use molecular biomarkers to identify the "progressive status" of a patient at any 1 time requiring treatment, or for recruiting patients into a clinical trial, is of great value and importance. Previously, a combination of biomarkers such as CTX-II in combination with a biomarker of type IIA collagen biosynthesis pointed to the ability to identify groups of patients that exhibited subsequent OA progression ${ }^{22}$. This evidence of an imbalance in collagen turnover in those who progress was also noted by Cahue, et $a l^{10}$ using the ratio of the $\mathrm{sC} 2 \mathrm{C}$ and serum c-propeptide of type II collagen assays, although the differences were not significant. The observation that this new urine assay alone is predictive of progression, in those with existing cartilage pathology, is thus of significant value in therapy and clinical trial recruitment, because it has the capacity to enrich study populations with progressors and potentially to identify whether a treatment is preventing disease progression. Even more discriminatory results may be found in the future from a combination of IB-C2C-HUSA with other biomarkers.

This study has several limitations. We did not include an asymptomatic control group. Our definition of cartilage worsening took into account only change in lesion depth, not lesion area extent, which may lead to underestimation of cartilage worsening. Serum and urine specimens were obtained at various times of day, potentially resulting in greater variability. Despite this, we found significant associations with disease status and progression. The strengths of our study include the evaluation of a population-based cohort, which allows for generalizability of results to the symptomatic population at large, and the inclusion of the full spectrum of knee OA severity, which enhances our understanding of the early preradiographic stage of disease.

We have demonstrated significant associations of the new urine IB-C2C-HUSA immunoassay with cartilage damage

$$
\text { Personal non-commercial use only. The Journal of Rheumatology Copyright (c) 2016. All rights reserved. }
$$


cross-sectionally and with cartilage loss longitudinally in a population-based cohort of early preradiographic disease and radiographic OA. Our study confirms the association of collagenase activity with radiographic OA, but also further points to the association of increased collagenase activity in early preradiographic articular cartilage degeneration and highlights its importance as a therapeutic target in cartilage degeneration.

\section{ACKNOWLEDGMENT}

We thank Dr. John M. Esdaile for his mentorship in obtaining funding for the original cross-sectional study ${ }^{11}$.

\section{ONLINE SUPPLEMENT}

Supplementary data for this article are available online at jrheum.org.

\section{REFERENCES}

1. Mitchell PG, Magna HA, Reeves LM, Lopresti-Morrow LL, Yocum SA, Rosner PJ, et al. Cloning, expression, and type II collagenolytic activity of matrix metalloproteinase-13 from human osteoarthritic cartilage. J Clin Invest 1996;97:761-8.

2. Dejica VM, Mort JS, Laverty S, Percival MD, Antoniou J, Zukor DJ, et al. Cleavage of type II collagen by cathepsin $\mathrm{K}$ in human osteoarthritic cartilage. Am J Pathol 2008;173:161-9.

3. Hollander AP, Heathfield TF, Webber C, Iwata Y, Rorabeck C, Bourne R, et al. Increased damage to type II collagen in osteoarthritic cartilage detected by a new immunoassay. J Clin Invest 1994;93:1722-32.

4. Hollander AP, Pidoux I, Reiner A, Rorabeck C, Bourne R, Poole AR. Damage to type II collagen in ageing and osteoarthritis starts at the articular surface, originates around chondrocytes and extends into the cartilage with progressive degeneration. J Clin Invest 1995;96:2859-69.

5. Billinghurst RC, Dahlberg L, Ionescu M, Reiner A, Bourne R, Rorabeck C, et al. Enhanced cleavage of type II collagen by collagenases in osteoarthritic articular cartilage. J Clin Invest 1997;99:1534-45.

6. Wu W, Billinghurst RC, Pidoux I, Antoniou J, Zukor D, Tanzer M, et al. Sites of collagenase cleavage and denaturation of type II collagen in articular cartilage in ageing and osteoarthritis and their relationship to the distribution of the collagenases MMP-1 and MMP-13. Arthritis Rheum 2002;46:2087-94.

7. Dejica V, Mort JS, Laverty S, Antoniou J, Zukor DJ, Tanzer M, et al Increased type II collagen cleavage by cathepsin $\mathrm{K}$ and collagenase activities with aging and osteoarthritis in human articular cartilage. Arthritis Res Ther 2012;14:R113.

8. Poole AR, Ionescu M, Fitzcharles MA, Billinghurst RC. The assessment of cartilage degradation in vivo: Development of an immunoassay for the measurement in body fluids of type II collagen cleaved by collagenases. J Immunological Methods 2004; 294:145-53.

9. Squires G, Okouneff S, Ionescu M, Poole AR. Pathobiology of focal lesion development in aging human articular cartilage reveals molecular matrix changes characteristic of osteoarthritis. Arthritis Rheum 2003;48:1261-70.
10. Cahue S, Sharma L, Dunlop D, Ionescu M, Song J, Lobanok T, et al. The ratio of type II collagen breakdown to synthesis and its relationship with the progression of knee osteoarthritis Osteoarthritis Cartilage 2007;15:819-23.

11. Cibere J, Zhang H, Garnero P, Poole AR, Lobanok T, Saxne T, et al. Association of biomarkers with pre-radiographically defined and radiographically defined knee osteoarthritis in a population-based study. Arthritis Rheum 2009;60:1372-80.

12. Nemirovskiy OV, Dufield DR, Sunyer T, Aggarwal P, Welsch DJ, Mathews WR. Discovery and development of a type II collagen neoepitope (TIINE) biomarker for matrix metalloproteinase activity: from in vitro to in vivo. Anal Biochem 2007;361:93-101.

13. Cibere J, Zhang H, Thorne A, Wong H, Singer J, Kopec J, et al. Association of clinical findings with pre-radiographic and radiographic knee osteoarthritis in a population based study. Arthritis Rheum 2010;62:1691-8.

14. Cibere J, Sayre EC, Guermazi A, Nicolaou S, Kopec JA, Esdaile JM, et al. Natural history of cartilage damage and osteoarthritis progression on magnetic resonance imaging in a population-based cohort with knee pain. Osteoarthritis Cartilage 2011;19:683-8.

15. Bellamy N, Buchanan WW, Goldsmith CH, Campbell J, Stitt LW. Validation study of WOMAC: a health status instrument for measuring clinically important participant relevant outcomes to antirheumatic drug therapy in participants with osteoarthritis of the hip or knee. J Rheumatol 1988;15:1833-40.

16. Kothari M, Guermazi A, von Ingersleben G, Miaux Y, Sieffert M, Block JE, et al. Fixed-flexion radiography of the knee provides reproducible joint space width measurements in osteoarthritis. Eur Radiol 2004;14:1568-73.

17. Kellgren JH, Lawrence JS. Radiological assessment of osteo-arthrosis. Ann Rheum Dis 1957;16:494-502.

18. Disler DG, McCauley TR, Kelman CG, Fuchs MD, Ratner LM, Wirth CR, et al. Fat-suppressed three-dimensional spoiled gradient-echo MR imaging of hyaline cartilage defects in the knee: comparison with standard MR imaging and arthroscopy. Am J Roentgenol 1996;167:127-32.

19. Downs JT, Lane CL, Nestor NB, McLellan TJ, Kelly MA, Karam GA, et al. Analysis of collagenase-cleavage of type II collagen using a neoepitope ELISA. J Immunological Methods 2001;247:25-34.

20. Sharif M, Kirwan JR, Elson CJ, Granell R, Clarke S. Suggestion of nonlinear or phasic progression of knee osteoarthritis based on measurements of serum cartilage oligomeric matrix protein levels over five years. Arthritis Rheum 2004;50:2479-88.

21. Kumm J, Tamm A, Lintrop M, Tamm A. The prevalence and progression of radiographic knee osteoarthritis over 6 years in a population-based cohort of middle-aged subjects. Rheumatol Int 2012;32:3545-50.

22. Garnero P, Ayral X, Rousseau J-C, Christgau S, Sandell L, Dougados M, et al. Uncoupling of type II collagen synthesis and degradation predicts progression of joint damage in patients with knee osteoarthritis. Arthritis Rheum 2002;46:2613-24. 